personal notes will help to keep the members of the Institute in touch with one another. If the present programme is continued, both the Institute and the Journal should help to fill the need that has long been felt for an organisation, commonwealth in scope, through which the views of the agricultural profession can be expressed.

\section{Monographs of Physiology}

Tне rapid advance in our knowledge in every branch of scientific inquiry makes it difficult or impossible for investigators to follow the work which is being carried out in other fields than their own in any great detail. Even in their own particular sphere, they must rely for their knowledge of the literature to a certain extent upon the abstract and review journals. For this reason, we welcome the short monographs on different subjects which are now being published in Paris : the earlier series dealt with problems of physics and physical chemistry, but during the past year various monographs on physiological questions have been issued (Actualités Scientifiques et Industrielles. Nos. 113, 135 and 136, 178 and 179. 1934. Paris : Hermann et Cie). No. 113 in the series, by T. Cahn and J. Houget, gives a short account of the biochemistry of muscular contraction. The four chapters deal with the chemical changes occurring in a muscle extract, in an isolated muscle and in the intact animal during muscular work: the fourth summarises our knowledge. There are no references. Nos. 135 and 136, by Z. M. Bacq, give short accounts of sympathicomimetic substances and of the hormones and vitamins : bibliographies are included. The first gives a brief account of substances which produce the same, or similar, effects in the body as stimulation of the true sympathetic nerves, and discusses their mode of action. The second reviews briefly our present knowledge of the hormones and vitamins, especially from the point of view of the minuteness of the quantity which is active in the body. Nos. 178 and 179 , by F. Kayser, deal with the biochemistry and physiology of creatine and creatinine, including their metabolism in health and disease. The subject is treated more fully than in the other monographs and the bibliography occupies about one third of each volume. Each gives an excellent review of our present knowledge of the functions of these compounds in the body, and is worth perusal by those interested.

\section{University Degrees in Engineering}

THE series of articles in the Engineer on "University Degrees in Engineering", to which we directed attention some time ago, have now been republished as a booklet (London: Morgan Brothers (Publishers), Ltd., 1s.). The author of the articles is Dr. T. W Chalmers, and the survey has been prepared from information contained in official publications of the nineteen universities of Great Britain and Ireland. The survey does not pretend to cover all the essential features of the regulations, and matters connected with matriculation and entrance examinations have been excluded. The booklet should prove of use to everyone interested in engineering education.

\section{Rabies in South Africa}

IN the Onderstepoort Journal of Veterinary Science and Animal Industry for October 1934 (3, No. 2, p. 335), attention is directed to the increase in South Africa in the incidence of rabies in 1933 over 1932. The disease occurs, and appears to be spreading, among the small wild carnivora (Viverridoe). The disease was definitely proved in twenty animals, and in addition nine calves and three cows almost certainly died from it. There were six cases in man, transmitted once by a dog, twice by the domestic cat, once by a wild cat, and twice by the yellow mungoose (Cynictis).

\section{The Case for Vivisection}

AN article with this title, by a 'layman', Mr. J. Alderson, appears in the Research Defence Society's journal the Fight against Disease (No. 2, 1935). The author points out that experiments on animals in Great Britain are rigorously controlled by Act of Parliament; but it is his conviction that were there no such Act, vivisection would be carried out just as humanely as it is now, for a love of animals and abhorrence of wilful cruelty are as evident among medical men as among other citizens. He concludes by stating that he feels he must support and defend the work on account of the discoveries made through experiments on animals, and that whenever relevant information can be so obtained, it is our duty to encourage and support it.

\section{Nutrition Research at the Mellon Institute}

During 1934, Dr. Gerald J. Cox and Miss Mary L. Dodds, working on a fellowship at Mellon Institute of Industrial Research, investigated fundamental causes of tooth decay. Their work suggested the existence of a factor which, if present in the diet during a critical period of tooth formation, will aid in the construction of teeth resistant to decay. This research is to be continued, along broad lines, through a grant for a period of one year from the Buhl Foundation of Pittsburgh. The investigation, which will be known as the Institute's multiple fellowship on nutrition, will be carried on by Dr. Cox as senior fellow, Miss Dodds as the junior incumbent, and W. E. Walker as the assistant, in the Department of Research in Pure Chemistry of the Institute. It is planned first to determine definitely whether or not this factor actually exists, and, if so, its nature, properties, distribution and extraction. Secondly, studies will be made of physiological processes which are likely to influence the development of dental caries.

\section{Award for Research in Fruit Growing}

IN 1920 Miss L. Jones-Bateman of Cae Glas, Abergele, presented to the Royal Horticultural Society a valuable silver-gilt replica of the Warwick Vase, to be used for the encouragement of fruit production. It has accordingly been decided to offer it triennially for researches in the growing of hardy fruits, figs, grapes and peaches in the open or under glass, and it is available for award in 1935. Candidates 